\title{
Prevalence of human papillomavirus infection and genotype distribution among high-risk Korean women for prospecting the strategy of vaccine development
}

\author{
Jee Eun Rhee', Mi Yeong Shin², Choong Mo Kim², Hye Young Kee ${ }^{3}$, Jae Keun Chung ${ }^{3}$, Sang-Kee Min ${ }^{4}$, \\ Seong-Joon Kim", Dai-Ho Jang ${ }^{1}$, Sung Soon Kim', Byeong-Sun Choi ${ }^{1^{*}}$
}

\begin{abstract}
We investigated the prevalence of human papillomavirus (HPV) infection and the distribution of high-risk HPV genotypes among 2,308 high-risk Korean women to predict how much the current prophylactic HPV vaccines might affect the prevention of cervical cancer in Korea. HPV DNA was detected in 939 women (40.7\%) but only one-third of women were positive for HPV-16 and/or HPV-18, the genotypes used for developing the HPV vaccines. Thus, the development of area-specific HPV vaccines based on dominant HPV genotypes in our country is needed for preventing HPV infection and the development of premalignant lesions in the cervix of Korean women.
\end{abstract}

\section{Findings}

Infection with certain types of human papillomavirus (HPV) is recognized as a causal and necessary factor for developing cervical cancer [1,2], which is the fourth of the most common cancer in South Korean women [3]. More than 140 different HPV genotypes have been characterized and approximately 50 of these genotypes are known to infect the genital tract and be oncogenic or high-risk (HR) types (HPV-16, -18, -31, -33, -35, -39, $-45,-51,-52,-56,-58,-59,-66$ and -68$)$. HR genotypes are significantly associated with progression to invasive cervical cancer [2,4]. Therefore, assessment of the HPV genotypic spectrum among sexually active women is important for predicting public health problems such as the risks of developing cervical intraepithelial neoplasia and cervical cancer $[5,6]$.

HPV-16, the most common HR type, is detected in 50 - $60 \%$ of high-grade squamous intraepithelial lesions and invasive cervical cancers and HPV-18 is followed by an incidence of $10-20 \%[4,7]$. Thus, HPV-16 and -18 are considered as the types responsible for causing most

\footnotetext{
* Correspondence: byeongsun@korea.kr

'Division of AIDS, Center for Immunology and Pathology, National Institute of Health, Korea Centers for Disease Control and Prevention, Seoul, Korea Full list of author information is available at the end of the article
}

cervical cancers in many countries [4,7]. Clinical trials have reported that these vaccines can protect many uninfected women from developing precancerous cervical lesions caused by HPV-16 and $-18[8,9]$. In spite of their high effectiveness to reduce the incidence of cervical cancer, the usefulness of these vaccines is still being debated because of the differences in the geographical distribution of HPV genotypes [10].

Vaccines against HPV-16 and -18 have been developed to help the prevention of cervical cancer and the use of Merck's Gardasil (the quadrivalent vaccine for HPV-6, -11, -16 and -18) and GSK's Cervarix (the bivalent vaccine for HPV-16 and -18) have been licensed by the Korea Food and Drug Administration. Populationbased study for the distribution of HPV genotype is needed to predict how much these vaccines might influence to the prevention of cervical cancer.

In the present study, the prevalence and distribution of HPV genotypes among high-risk women, which are called as commercial sex workers (CSWs) by other countries, were examined to predict whether the developed HPV vaccines are sufficient for preventing HPV infection and the development of premalignant lesions of the cervix in South Korea. 
A cohort of 2,308 high-risk women visiting for regular sexually transmitted infection testing in public health centers in four different regions (Seoul, Busan, Gwangju and Jeollanamdo) was enrolled in this study. Specimens were collected with a cytobrush for HPV testing, placed in viral transport medium (Cellmatics Viral Transport Pack, BD Diagnostics, Franklin Lakes, NJ, USA) and stored at $4^{\circ} \mathrm{C}$ until the use for experiment. Genomic DNA was extracted from cervical swabs by using an AccuPrep Genomic DNA Extraction Kit (Bioneer Co., Seoul, South Korea) according to the manufacturer's instructions. Purified DNA was used to detect HPV DNA and to determine the genotypes by using a HPV DNA Chip (Biocore Co. Ltd., Seoul, South Korea). 939 out of 2,308 specimens were HPV positive and HPV genotypes were typed using the HPV DNA Chip with 32 type-specific probes (HR types: HPV-16, -18, -26, $-31,-33,-35,-39,-45,-51,-52,-53,-56,-58,-59,-66$, -68 and -69 ; low-risk [LR] types: HPV-6, $-11,-32,-34$, $-40,-42,-43,-44,-54,-55,-57,-61,-62,-70$ and -73$)$.

The overall prevalence of HPV infection in these highrisk women was 40.7\%. HPV genotypes among 939 HPV-infected women were detected in 431 (45.9\%) for HR types and 147 (15.7\%) for LR types, respectively. 147 (15.7\%) women were infected with both genotypes. HPV prevalence was decreased with age and the highest HPV prevalence was observed in women under the age of 24 years old (Figure 1). The predominant HPV genotypes in this study were HPV-16 (23.0\%), HPV-58 (9.8\%), and HPV-18 (8.7\%) (Figure 2). The number of HPV-infected women with HPV-16 and -18 were 107 (11.4\%) and 43 (4.6\%) in a single-type infection and 109 (11.6\%) and 39 (4.2\%) in multiple-type infections, respectively (Table 1).

The prevalence of HPV infection in female CSWs from other countries was $57 \%$ in the Philippines [11], 39\% in Spain [12], 32\% in Australia [13] and 48\% in Japan [14]. In our previous data [15], the prevalence of HPV infection in high-risk women was $47 \%$ with the Hybrid Capture II method (Digene Diagnostics). Although the HPV prevalence among CSWs differs between countries, it was much higher than among low-risk women and men [16]. In addition, the prevalence of HPV infection in this study was lower than our previous study. This result may be generated by higher sensitivity of the Hybrid Capture assay compared to the DNA chip method and different population examined. The higher prevalence of HPV infection in younger women and the decreasing trend with age has been described by many other studies $[12,17]$. The inverse relation between age and HPV prevalence has been attributed to the development of acquired HPV immunity over time after HPV exposure $[17,18]$.

In this study, HPV-16 and -18 were detected only $31.7 \%$ including single or multiple infections in HPVinfected high-risk women (Table 1). The most prevalent HPV genotype was HPV-16 and next dominant type was the HPV-58 (Figure 2). According to Shin et al. [16], the prevalence of HPV infection for female university students in Busan was $15.2 \%$ and the common HPV genotypes were HPV-51, -53, -56, -16 and -52. In CSWs in the Philippines, HPV-52 was the most prevalent

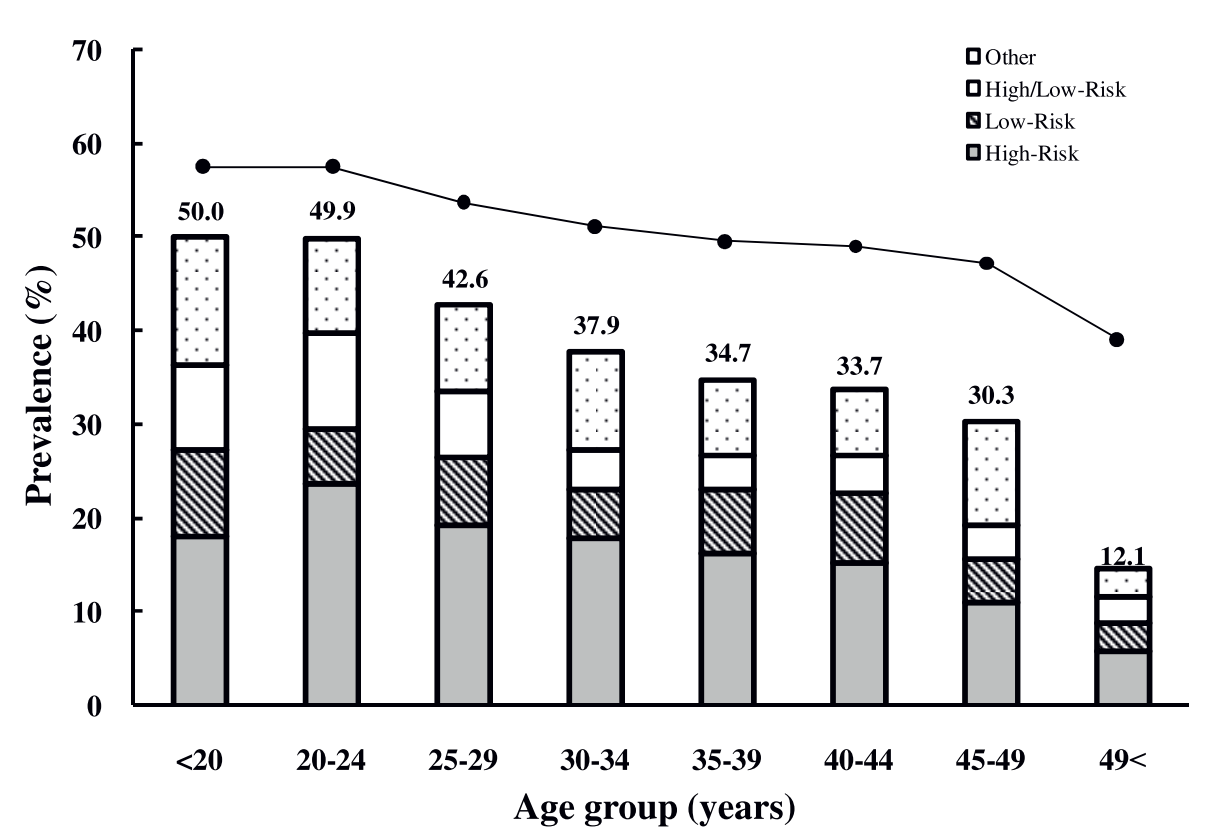

Figure 1 The distribution of HPV prevalence by age group. Age groups were defined based on age at enrollment into the study. 


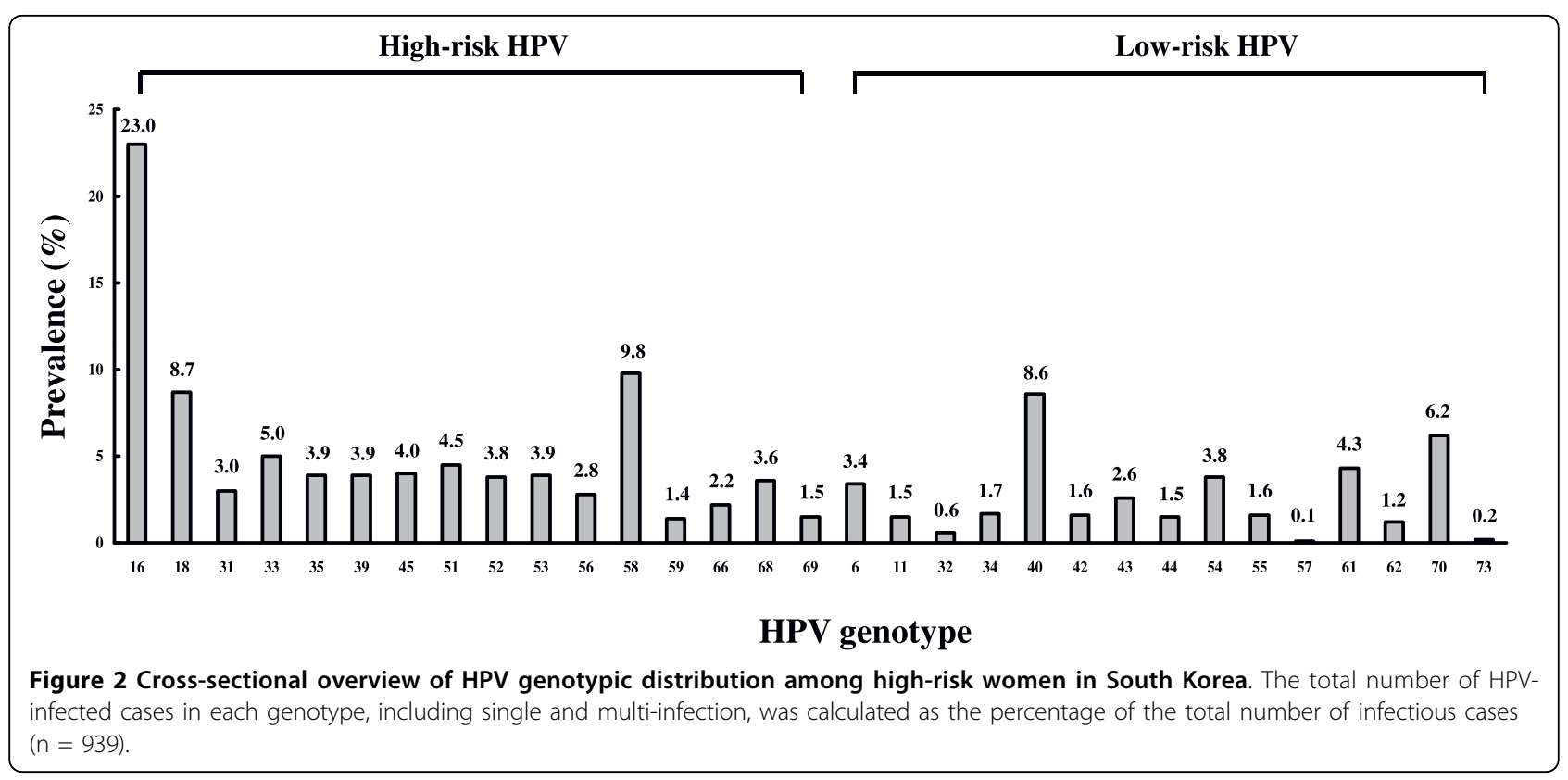

genotype and other dominant types were HPV-66, -16, -45 and -67 [11]. Among general gynecology practices in South Taiwan, the prevalent genotypes were HPV-16, $-52,-58,-18$ and -51 [19]. These results suggest that the predominant HPV genotypes such as HPV-58, -52 and -51 in Asian countries as well as HPV-16 might play some important roles in cervical carcinogenesis in these countries.

Even if clinical trials of prophylactic vaccines targeted for HPV-16 and -18 showed dramatically preventive effect for HPV infection and precancerous lesions, the cross-protection between various HPV genotypes is still unsolved in vaccinated women [20]. These results indicate that area-specific HPV vaccines should be developed for preventing HPV infection and the subsequent development of premalignant lesions of the cervix in Korean women.

\section{List of abbreviations}

HPV: human papillomavirus; HR: high-risk; LR: low-risk; CSWs: commercial sex workers

\section{Competing interests}

The authors declare that they have no competing interests.

\section{Authors' contributions}

MY, CM, HY, JK, SK, SJ collected the samples and carried out the experiments. DH and SS participated in the design of the study and supported performing of experiments. JE and BS designed the research and wrote and edited the manuscript. All authors read and approved the final manuscript.

Table 1 Distribution of high-risk women infected with HPV-16 and/or HPV-18 genotypes and with single or multiple infections by age group $(n=939)$

\begin{tabular}{ccccc}
\hline Age (years) & \multicolumn{2}{c}{ No. of HPV-16-infected women (\%) } & \multicolumn{2}{c}{ No. of HPV-18-infected women (\%) } \\
\cline { 2 - 5 } & Single & Multiple & Single & Multiple \\
\hline$<20$ & $1(0.9)$ & $3(2.8)$ & $0(0.0)$ & $2(5.1)$ \\
$20-24$ & $28(26.2)$ & $17(15.6)$ & $11(25.6)$ & $6(15.4)$ \\
$25-29$ & $31(29.0)$ & $41(37.6)$ & $7(39.5)$ & $12(30.8)$ \\
$30-34$ & $22(20.6)$ & $7(6.4)$ & $5(11.6)$ & $3(7.7)$ \\
$35-39$ & $13(12.1)$ & $4(3.7)$ & $4(9.3)$ & $0(0.0)$ \\
$40-44$ & $6(5.6)$ & $5(4.6)$ & $0(0.0)$ & $2(5.1)$ \\
$45-49$ & $5(4.7)$ & $1(0.9)$ & $0(0.0)$ & $0(0.0)$ \\
$>49$ & $1(0.9)$ & $0(0.0)$ & $43(4.6)$ & $0(0.0)$ \\
\hline Total & $107(11.4)$ & $109(11.6)$ & & $39(4.1)$ \\
\hline
\end{tabular}




\section{Acknowledgements}

This work was supported by an intramural fund (No. 2008-N00386-00) and regional diagnostic infra-structure project (2006-2008) from the National Institute of Health, Republic of Korea.

\section{Author details}

'Division of AIDS, Center for Immunology and Pathology, National Institute of Health, Korea Centers for Disease Control and Prevention, Seoul, Korea. ${ }^{2}$ Division of Microbiology, Jeollanam-Do Institute of Health and Environment, Jeollanamdo, Korea. ${ }^{3}$ Department of Health Research, Gwangju Institute of Health and Environment, Gwangju, Korea. ${ }^{4}$ Division of Epidemiology, Busan Institute of Health and Environment, Busan, Korea.

Received: 26 May 2010 Accepted: 25 August 2010

Published: 25 August 2010

\section{References}

1. Bosch FX, Lorincz A, Munoz N, Meijer CJ, Shah KV: The causal relation between human papillomavirus and cervical cancer. J Clin Pathol 2002, 55:244-265.

2. Walboomers JM, Jacobs MV, Manos MM, Bosch FX, Kummer JA, Shah KV, Snijders PJ, Peto J, Meijer CJ, Munoz N: Human papillomavirus is a necessary cause of invasive cervical cancer worldwide. J Pathol 1999, 189:12-19.

3. Shin HR, Won YJ, Jung KW, Kong HJ, Yim SH, Lee JK: Nationwide cancer incidence in Korea 1999-2001; First result using the national cancer incidence database. Cancer Res Treat 2005, 37:325-331.

4. Munoz N, Bosch FX, De Sanjose S, Herrero R, Castellsague X, Shah KV, Snijders PJ, Meijer CJ: Epidemiologic classification of human papillomavirus types associated with cervical cancer. N Engl J Med 2003, 348:518-527.

5. Chan PK, Mak KH, Cheung JL, Tang NL, Chan DP, Lo KK, Cheng AF: Genotype spectrum of cervical human papillomavirus infection among sexually transmitted disease clinic patients in Hong Kong. J Med Virol 2002, 68:273-277.

6. Pretet JL, Jacquard AC, Carcopino X, EDITH study group: Human papillomavirus genotype distribution in high grade cervical lesions (CIN 2/3) in France: EDITH study. Int J Cancer 2008, 122:424-427.

7. Bae JH, Lee SJ, Kim CH, Hur SY, Park YG, Lee WC, Kim YT, Ng TL, Bock HL, Park JS: Human papillomavirus (HPV) type distribution in Korean women: a meta-analysis. J Microbiol Biotechnol 2008, 18:788-794.

8. Adult KA, Future II Study group: Effect of prophylactic human papillomavirus L1 virus-like-particle vaccine on risk of cervical intraepithelial neoplasia grade 2, grade 3 , and adenocarcinoma in situ: a combined analysis of four randomized clinical trials. Lancet 2007, 369:1861-1868.

9. Paavonen J, Jenkins D, Bosch FX, HPV PATRICIA Study Group, et al: Efficacy of a prophylactic adjuvanted bivalent $\mathrm{L} 1$ virus-like-particle vaccine against infection with human papillomavirus types 16 and 18 in young women: an interim analysis of a Phase III double-blind, randomized controlled trial. Lancet 2007, 369:2161-2170.

10. Cutts FT, Franceschi S, Goldie S, Castellsague X, De Sanjose S, Garnett G, Edmunds WJ, Claeys P, Goldenthal KL, Harper DM, Markowitz L: Human papillomavirus and HPV vaccines: a review. Bull World Health Organ 2007, 85:719-726.

11. Miyashita M, Agdamag DM, Sasagawa T, Matsushita L, Salud LM, Salud CO, Saikawa K, Leano PS, Pagcaliwagan T, Acuna J, Ishizaki A, Kageyama S, Ichimura H: High-risk HPV types in lesions of the uterine cervix of female commercial sex workers in the Philippines. J Med Virol 2009, 81:545-551.

12. Del Amo J, Gonzalez C, Losana J, Clavo P, Munoz L, Ballesteros J, GarciaSaiz A, Belza MJ, Ortiz M, Menendez B, Del Romero J, Bolumar F: Influence of age and geographical origin in the prevalence of high risk human papillomavirus in migrant female sex workers in Spain. Sex Transm Infect 2005, 81:79-84

13. Tideman RL, Thompson C, Rose B, Gilmour S, Marks C, Van Beek I, Berry G, O'Connor C, Mindel A: Cervical human papillomavirus infections in commercial sex workers - risk factors and behaviours. Int J STD AIDS 2003, 14:840-847.

14. Ishi K, Suzuki F, Saito A, Kubota T: Prevalence of human papillomavirus, Chlamydia trachomatis and Neisseria gonorrhoeae in commercial sex workers in Japan. Infect Dis Obstet Gynecol 2000, 8:235-239.
15. Choi BS, Kim O, Park MS, Kim KS, Jeong JK, Lee JS: Genital human papillomavirus genotyping by HPV oligonucleotide microarray in Korean commercial sex workers. J Med Virol 2003, 71:440-445.

16. Shin HR, Franceschi S, Vaccarella S, Roh JW, Ju YH, Oh JK, Kong HJ, Rha SH, Jung Sl, Kim Jl, Jung KY, Van Doorn LJ, Quint W: Prevalence and determinants of genital infection with papillomavirus, in female and male university students in Busan, South Korea. J Infect Dis 2004, 190:468-476.

17. Burk RD, Kelly P, Feldman J, Bromberg J, Vermund SH, DeHovitz JA, Landesman SH: Declining prevalence of cervicovaginal human papillomavirus infection with age is independent of other risk factors. Sex Transm Dis 1996, 23:333-341.

18. Kjaer SK, Svare El, Worm AM, Walboomers JM, Meijer CJ, Van den Brule AJ: Human papillomavirus infection in Danish female sex workers. Decreasing prevalence with age despite continuously high sexual activity. Sex Transm Dis 2000, 27:438-445.

19. Lin H, Ma YY, Moh JS, Ou YC, Shen SY, Changchien CC: High prevalence of genital human papillomavirus type 52 and 58 infection in women attending gynecologic practitioners in South Taiwan. Gynecol Oncol 2006, 101:40-45.

20. Harper DM: Prophylactic human papillomavirus vaccines to prevent cervical cancer: review of the phase II and III trials. Therapy 2008, 5:313-324

doi:10.1186/1743-422X-7-201

Cite this article as: Rhee et al:: Prevalence of human papillomavirus infection and genotype distribution among high-risk Korean women for prospecting the strategy of vaccine development. Virology Journal 2010 7:201.

\section{Submit your next manuscript to BioMed Central and take full advantage of:}

- Convenient online submission

- Thorough peer review

- No space constraints or color figure charges

- Immediate publication on acceptance

- Inclusion in PubMed, CAS, Scopus and Google Scholar

- Research which is freely available for redistribution
C Biomed Central 